\title{
Study on Radial Suspension Forces of Bearingless Permanent Magnet Slice Motor Based on Accurate Inductance Model
}

\author{
Huangqiu Zhu, Suming Zhu \\ School of Electrical and Information Engineering, Jiangsu University, 212013 Zhenjiang, China, \\ E-mail: xiaoming1106.happy@163.com
}

\begin{abstract}
An accurate mathematical model of radial suspension forces for a bearingless permanent magnet slice motor (BPMSM) is of great significance to levitate the rotor stably and to improve the control accuracy of radial suspension force. In this paper, after a brief introduction on the suspension principle of the BPMSM, the accurate inductance model of two sets of stator windings (torque windings and bearing windings) is deduced. Based on the accurate inductance model and taking rotor eccentricity into account, a complete and precise mathematical model of radial suspension forces of the BPMSM is obtained. In order to confirm the validity and feasibility of this mathematical model, the experiments are carried out on a $4 \mathrm{~kW}$ prototype of the BPMSM. The experimental results show that the control system designed by using this method has high control accuracy of radial suspension force, strong capability of resisting disturbance, and good static and dynamic performance.
\end{abstract}

Index Terms - bearingless permanent magnet slice motor (BPMSM), radial suspension force, inductance, mathematical model

\section{INTRODUCTION}

BPMSM (bearingless permanent magnet slice motor) is a new type of bearingless motors, whose axial length of rotor is small compared with the diameter, in this case, the stabilization of slice rotor for the axial and two tilt deflections (left-right tilt and forth-back tilt) can be achieved by passive suspension forces and the active stabilization degrees are reduced to the two radial deflections only [1-2]. The BPMSM not only has all the advantages of magnetic bearing such as mechanical contact-free, no mechanical noise, no wear, no lubrication, long operating life, high speed and precision, but also has the superiority of small structure, high power density and high stability. The absolute stabilization of slice rotor makes high sealing available, therefore, the BPMSM has a wide range of applications in the fields of special electric drives such as high-speed-precision mechanical processing, aeronautics and astronautics, life science, canned pumps, semiconductor and biotechnology industries [1]-[5].

It's indispensable for a bearingless motor's high-precision operation to establish an accurate model of radial suspension forces. Over the past decades, some typical models of radial suspension forces have been put forward. In literature [6], the model of radial suspension forces for the single-windings BPMSM is proposed on the basis of equivalent circuit method, however, the coupling is serious because the magnetic field of torque windings and 
magnetic field of bearing windings are generated by the currents of a single windings. In literature [7], segmentation method for a consequent-pole permanent magnet bearingless motor is applied to establish the mathematical model of radial suspension forces. But in the model, there exist air-gap width $l_{\mathrm{g}}$ and thickness $l_{\mathrm{m}}$ of permanent magnet that affect the ripple of radial suspension forces, and it's not good for the accurate and stable control of the motor. In literature [8], a relatively accurate model of radial suspension forces, which takes eccentricity and the coupling relationship of windings into account, is derived, but it does not consider the difference between the inductance model in the 2-phase stator coordinate system and that in the 2-phase rotor synchronous coordinate system, therefore, the mathematical model of radial suspension forces is still not accurate enough.

In this paper, after a brief introduction on the suspension principle of the BPMSM, the accurate inductance model of the two sets of stator windings are deduced. Then based on the accurate inductance model and taking rotor eccentricity into account, a complete and precise mathematical model of radial suspension forces of the BPMSM is established. Eventually, the corresponding control system is designed and the experiments are carried out on a $4 \mathrm{~kW}$ prototype of the BPMSM. The experimental results show that the control system based on the proposed model of radial suspension forces has high control accuracy of radial suspension force, fine anti-disturbance, and good static and dynamic performance.

\section{SUSPENSION PRINCIPLE OF BPMSM}

According to the similarity between motor and magnetic bearings, a bearingless motor can be got when the bearing windings are added in the stator of motor itself. In this paper, the torque windings and bearing windings of the BPMSM, whose numbers of pole pairs are $P_{\mathrm{M}}=1$ and $P_{\mathrm{B}}=2$, respectively, each has six concentrated coils rounded on six iron core legs as shown in Fig. 1. The detailed parameters of the BPMSM prototype are shown in TABLE I.

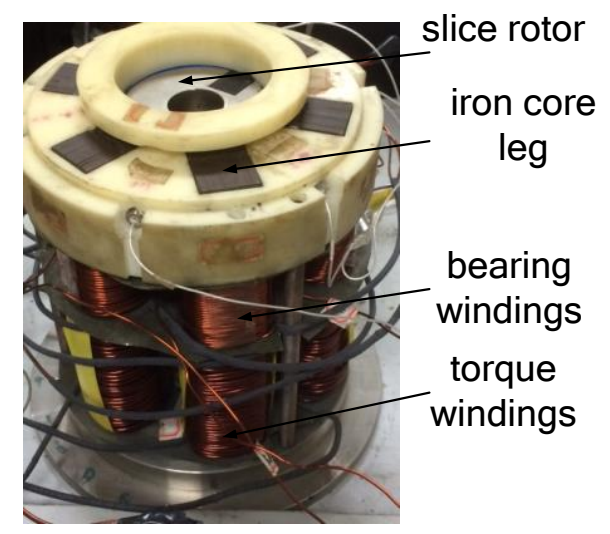

Fig. 1. The prototype of BPMSM

TABLE I PARAMETERS OF BPMSM

\begin{tabular}{ccc}
\hline Symbol & TABLE I PARAMETERS OF BPMSM & Quantity \\
\hline$D_{\mathrm{S} 1}$ & outer diameter of stator $(\mathrm{mm})$ & 200 \\
$D_{\mathrm{S} 2}$ & inner diameter of stator $(\mathrm{mm})$ & 84 \\
$D_{r 1}$ & outer diameter of rotor $(\mathrm{mm})$ & 80 \\
$D_{r 2}$ & inner diameter of rotor $(\mathrm{mm})$ & 30 \\
\hline
\end{tabular}




\begin{tabular}{ccc}
\hline$D_{\mathrm{B} 1}$ & outer diameter of bottom iron core yoke $(\mathrm{mm})$ & 164 \\
$D_{\mathrm{B} 2}$ & inner diameter of bottom iron core yoke $(\mathrm{mm})$ & 114 \\
$L_{\mathrm{g}}$ & length of air-gap $(\mathrm{mm})$ & 2 \\
$l$ & axial length of rotor $(\mathrm{mm})$ & 20 \\
$P$ & rated power $(\mathrm{kW})$ & 4 \\
& material of stator & Steel_10 \\
& material of permanent magnet rotor & NFeB35 \\
$m$ & magnetization of permanent magnet rotor & parallel magnetization \\
$P_{\mathrm{M}}$ & quality of slice rotor $(\mathrm{kg})$ & 1 \\
$P_{\mathrm{B}}$ & pole pairs of torque windings & 1 \\
$P_{\mathrm{PM}}$ & pole pairs of bearing windings & 2 \\
$W_{1}$ & pole pairs of slice rotor & 1 \\
$W_{2}$ & turns of torque windings & 100 \\
$J$ & turns of bearing windings & 100 \\
\hline
\end{tabular}

The currents in torque windings and bearing windings generate magnetic fields of torque windings and bearing windings, respectively. As a function of the two magnetic fields with different numbers of pole pairs, the original balanced air-gap magnetic field is broken and in this case a radial suspension force can be generated to realize the stabilization of rotor. Fig. 2 shows the magnetic circuits and active suspension force generation principle of the BPMSM. The axial and radial sectional views of magnetic circuits are shown in Fig. 2(a) and Fig. (b), respectively. As shown in Fig. 2(a), the magnetic force lines of torque windings pass through two spatial opposite iron core legs, bottom magnetic yoke, air gap and permanent magnet slice rotor (The magnetic force lines of bearing windings are similar and they pass through two adjacent iron core legs, bottom magnetic yoke, air gap and permanent magnet slice rotor. In Fig. 2(a), the magnetic force lines of bearing windings are not shown). The bottom magnetic yoke is ring-shaped and its ring width is equal to the radial width of the bottom part of six iron core legs. Its inner and outer diameter are $114 \mathrm{~mm}$ and $164 \mathrm{~mm}$, respectively.

In fact, when two windings are wound around columns parallel to the $\mathrm{z}$ direction (Fig. 2(a)) or wound around columns parallel to x-y plane (Fig. 2(b)), the generated magnetic fields are same. On basis of that, when the phases of magnetic fields of torque windings and bearing windings are both $0^{\circ}$, that is, the A-phase currents of torque and bearing windings both reach the maximum value, the equivalent paths of magnetic force lines in radial direction can be regarded as the ones in Fig. 2(b). In Fig. 2(b), the air-gap flux density in air gap 1 is weakened and by contrast, that in air gap 2 is strengthened, thus the motor generates the suspension force component $F_{\mathrm{x}}$ in x-direction. By changing the phases of two magnetic fields, active suspension force in any direction can be achieved. In Fig. 2(b), B- and C-phase of torque and bearing windings are not shown, $\mathrm{x}$-y coordinate system is the 2-phase stator coordinates and $\mathrm{x}$-axis coincides with the A-phase axes of two windings (torque windings and bearing windings). 


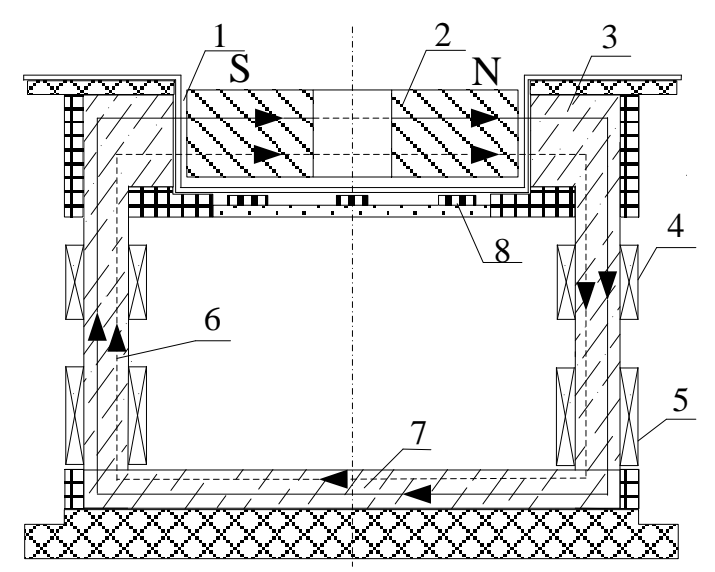

(a) the axial sectional view of magnetic circuits.

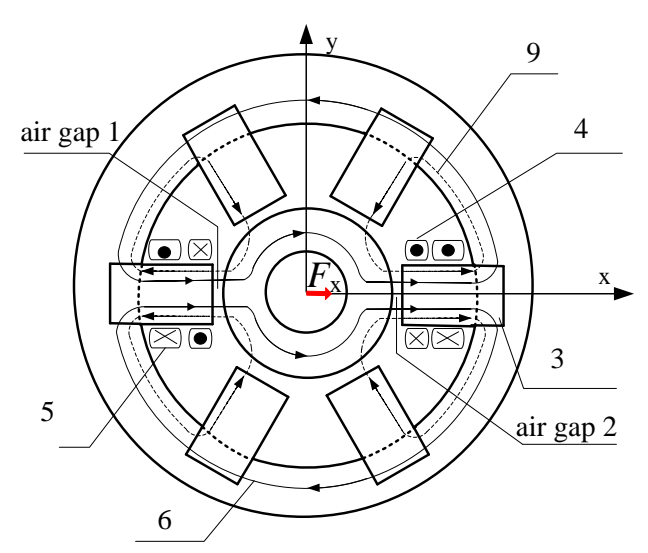

(b) radial sectional view of magnetic circuits.

1- air gap; 2- permanent magnetic slice rotor; 3 - iron core leg; 4-bearing windings;

5- motor windings; 6 - the flux linkage of motor windings; 7-bottom iron core yoke;

8- hall sensor; 9- the flux linkage of bearing windings

BPMSM needs to stabilize 5 degrees of freedom, besides two radial degrees of freedom, the axial and two tilt deflections also need to control. The passive suspension principle of the BPMSM is shown in Fig. 3. Fig. 3(a) shows an axial displacement of slice rotor, and two tilt deflections are shown in Fig. 3(b) and Fig. 3(c), respectively. The relationship between three passive degrees of freedom and three-dimensional cartesion coordinates is shown in Fig. 3(d). The origin $\mathrm{O}(0,0,0)$ is oriented in the space center of slice rotor. As the axial length of slice rotor is small compared with the diameter, these three degrees of freedom can be stabilized passively according to the property of magnetic resistance force [1]. That is, when the rotor has axial or two tilt deflections, it can return to the balanced position under the reverse effect of magnetic resistance forces. In Fig. 3, $F_{\mathrm{p}}$ represents the magnetic resistance forces acting on the rotor, $F_{\mathrm{p} 1}$ and $F_{\mathrm{p} 2}$ stand for the magnetic resistance force components in radial direction and axial direction, respectively.

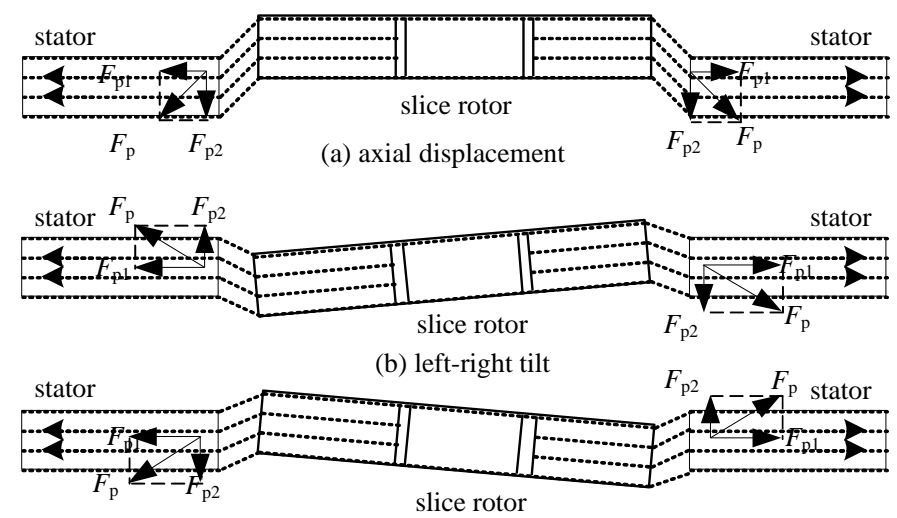

(c) forth-back tilt

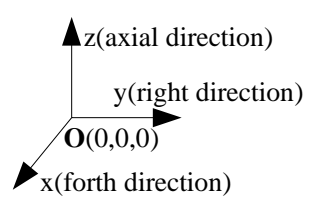

(d) the relationship between three passive degrees of freedom and three-dimensional cartesion coordinates

Fig. 3. Passive suspension force generation of BPMSM

Brazilian Microwave and Optoelectronics Society-SBMO Brazilian Society of Electromagnetism-SBMag received 22 May 2014; for review 27 May 2014; accepted 17 Dec 2014 (C) 2014 SBMO/SBMag
ISSN 2179-1074 


\section{THE MATRIX MODEL OF BPMSM}

\section{A. Inductance model of BPMSM in the 2-phase stator coordinate system}

According to the theories of motor control and coordinate transformation, both 3-phase torque windings and 3phase bearing windings can be transformed to 2-phase windings. The distribution of the two 2-phase windings of the BPMSM is shown in Fig. 4, in which $\gamma_{\mathrm{F}}$ represents the mechanical angular position of slice rotor, $2 \rho$ is the pole arcwidth of permanent magnet, $N_{\mathrm{a}}, N_{\mathrm{b}}$ and $N_{\omega}, N_{\beta}$ stand for torque windings and bearing windings, respectively. Assuming the effective air-gap range of permanent magnet surfaced on the rotor is $\Omega$, then it can be expressed as

$$
\Omega=\left\{\left(\gamma_{\mathrm{F}}-\rho, \gamma_{\mathrm{F}}+\rho\right),\left(\gamma_{\mathrm{F}}-\rho+\pi, \gamma_{\mathrm{F}}+\rho+\pi\right)\right\}
$$

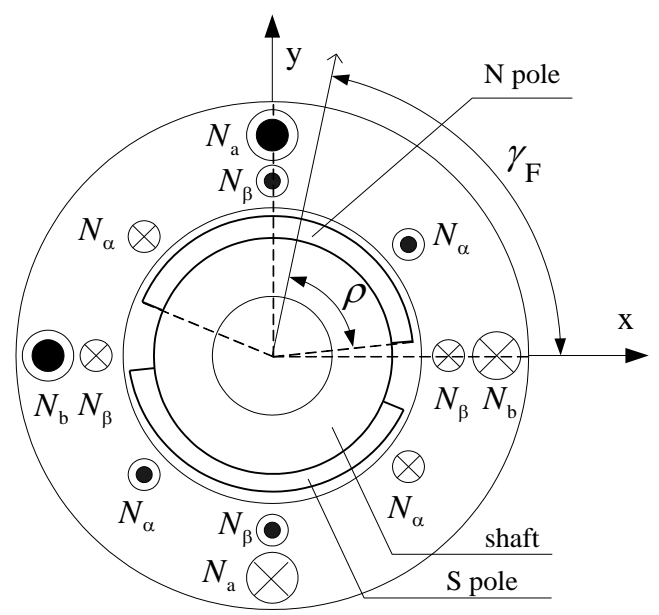

Fig. 4. The distribution of the two 2-phase windings of the BPMSM

In Fig. 5, $\mathrm{O}(0,0)$ is the center coordinates of slice rotor without eccentricity and $\mathrm{O}^{\prime}(x, y)$ is the one with eccentricity. $\theta$ is the spatial mechanical angle, $x$ and $y$ represent the eccentric components in the 2-phase stator coordinate system. Supposing that the unilateral average air-gap length between slice rotor and stator is $\delta_{0}$, the unilateral air-gap length is $\delta(\theta)$, and the change of unilateral air-gap length caused by eccentricity is $\Delta \delta$, then the unilateral air-gap length $\delta(\theta)$ can be written as

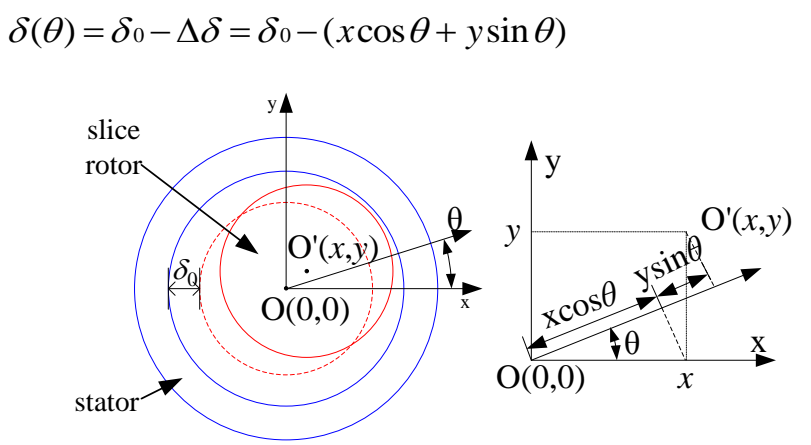

Fig. 5. The rotor eccentricity definition

The reciprocal of equation (2) can be written as

$$
\frac{1}{\delta(\theta)}=\frac{\delta_{0}+x \cos \theta+y \sin \theta}{\delta_{0}^{2}-x^{2} \cos ^{2} \theta-y^{2} \sin ^{2} \theta-x y \sin 2 \theta}
$$


In the running of the BPMSM, the eccentric components ( $x$ and $y)$ are relatively small compared to the unilateral average air-gap length $\delta_{0}$, omitting the squared terms and product terms, then equation (3) can be written as

$$
\frac{1}{\delta(\theta)} \approx \frac{1}{\delta_{0}^{2}}\left(\delta_{0}+x \cos \theta+y \sin \theta\right)
$$

The air-gap permeance per unit area along dimensional angle on the rotor surface can be expressed as

$$
d \Lambda(\theta)=\frac{\mu_{0} d s}{\delta(\theta)} \approx \frac{\mu_{0} l r}{\delta_{0}^{2}}\left(\delta_{0}+x \cos \theta+y \sin \theta\right) d \theta
$$

where $l$ is the axial length of slice rotor, $r$ is the radius of slice rotor and $\mu_{0}$ is permeability of vacuum.

In the model of the BPMSM shown in Fig. 4, the a-phase of torque windings and $\alpha$-phase of bearing windings coincide with the x-axis of 2-phase stator coordinate system. As the concentrated distribution of the two sets of windings, the distribution of windings along the circumferential air-gap is the periodic and rectangular wave form. Applying the Fourier series expansion to the windings and taking the fundamental windings into consideration only, the exact distribution formulations of the two sets of windings along the circumferential air-gap can be got as [9]

$$
\left\{\begin{array}{l}
A_{\mathrm{a}}=K w_{2} \cos \theta \\
A_{\mathrm{b}}=K w_{2} \sin \theta \\
A_{\alpha}=K w_{4} \cos 2 \theta \\
A_{\beta}=K w_{4} \sin 2 \theta
\end{array}\right.
$$

where $K$ is the amplitude of fundamental windings and $K=4 / \pi, w_{2}$ and $w_{4}$ are the effective turns per phase of torque windings and bearing windings, respectively.

In the operation of the motor, magnetic energy storage is reflected as the energy storage of inductance, therefore, in the calculation of the inductive parameters, the flux change caused by rotor eccentricity must be considered. Supposing that the current in the a-phase of torque windings is $i_{\mathrm{a}}$, if the flux drop in the iron core magnetic circuit is ignored, according to magnetic ohm's law, the air-gap flux per unit area along mechanical angle in the circumferential air-gap can be expressed as

$$
d \varphi(\theta)=\left(\frac{A_{\mathrm{a}}(\theta) i_{\mathrm{a}}}{2}-F_{\mathrm{a}}\right) d \Lambda(\theta)
$$

where $F_{\mathrm{a}}$ is a-phase magnetomotive force of rotor. According to the Gauss's law, the integration of the air-gap flux along the circumferential air-gap is zero, in this case, substituting equation (5) and equation (6) into equation (7), the a-phase magnetomotive force of rotor can be got as

$$
F_{\mathrm{a}}=\frac{K w_{2} i_{\mathrm{a}}}{4 \delta_{0}} x
$$

Similarly, b-, $\alpha$ - and $\beta$-phase magnetomotive force of rotor can be got as, respectively

$$
\left\{\begin{array}{l}
F_{\mathrm{b}}=\frac{K w_{2} i_{\mathrm{b}}}{4 \delta_{0}} y \\
F_{\alpha}=0, F_{\beta}=0
\end{array}\right.
$$


Substituting equation (8) and equation (9) into equation (7), the distribution formulations of flux per unit dimensional mechanical angle on the rotor surface in the range of $\Omega$ can be expressed as

$$
\left\{\begin{array}{l}
d \varphi_{\mathrm{a}}=\left(\frac{1}{2} K w_{2} i_{\mathrm{a}} \cos \theta-\frac{K w_{2} i_{\mathrm{a}}}{4 \delta_{0}} x\right) d \Lambda(\theta) \\
d \varphi_{\mathrm{b}}=\left(\frac{1}{2} K w_{2} i_{\mathrm{b}} \sin \theta-\frac{K w_{2} i_{\mathrm{b}}}{4 \delta_{0}} y\right) d \Lambda(\theta) \\
d \varphi_{\alpha}=\frac{1}{2} K w_{4} i_{\alpha} \cos 2 \theta d \Lambda(\theta) \\
d \varphi_{\beta}=\frac{1}{2} K w_{4} i_{\beta} \sin 2 \theta d \Lambda(\theta)
\end{array}\right.
$$

On the basis of the relationship between the motor flux and current, the inductance model of the two sets of windings in the effective air-gap range of permanent magnet $\Omega$ can be written as

$$
\left\{\begin{array}{l}
\boldsymbol{L}_{\mathrm{M}}=\left[\begin{array}{ll}
\int^{\Omega} \frac{1}{2 i_{\mathrm{a}}} A_{\mathrm{a}}(\theta) d \varphi_{\mathrm{a}}(\theta) & \int^{\Omega} \frac{1}{2 i_{\mathrm{b}}} A_{\mathrm{a}}(\theta) d \varphi_{\mathrm{b}}(\theta) \\
\int^{\Omega} \frac{1}{2 i_{\mathrm{a}}} A_{\mathrm{b}}(\theta) d \varphi_{\mathrm{a}}(\theta) & \int^{\Omega} \frac{1}{2 i_{\mathrm{b}}} A_{\mathrm{b}}(\theta) d \varphi_{\mathrm{b}}(\theta)
\end{array}\right] \\
\boldsymbol{L}_{\mathrm{B}}=\left[\begin{array}{ll}
\int^{\Omega} \frac{1}{2 i_{\alpha}} A_{\alpha}(\theta) d \varphi_{\alpha}(\theta) & \int^{\Omega} \frac{1}{2 i_{\beta}} A_{\alpha}(\theta) d \varphi_{\beta}(\theta) \\
\int^{\Omega} \frac{1}{2 i_{\alpha}} A_{\beta}(\theta) d \varphi_{\alpha}(\theta) & \int^{\Omega} \frac{1}{2 i_{\beta}} A_{\beta}(\theta) d \varphi_{\beta}(\theta)
\end{array}\right] \\
\boldsymbol{L}_{\mathrm{MB}}=\left[\begin{array}{ll}
\int^{\Omega} \frac{1}{2 i_{\alpha}} A_{\mathrm{a}}(\theta) d \varphi_{\alpha}(\theta) & \int^{\Omega} \frac{1}{2 i_{\beta}} A_{\mathrm{a}}(\theta) d \varphi_{\beta}(\theta) \\
\int^{\Omega} \frac{1}{2 i_{\alpha}} A_{\mathrm{b}}(\theta) d \varphi_{\alpha}(\theta) & \int^{\Omega} \frac{1}{2 i_{\beta}} A_{\mathrm{b}}(\theta) d \varphi_{\beta}(\theta)
\end{array}\right]
\end{array}\right.
$$

where $\boldsymbol{L}_{\mathrm{M}}$ and $\boldsymbol{L}_{\mathrm{B}}$ are the self-inductances of torque windings and bearing windings, respectively. $\boldsymbol{L}_{\mathrm{MB}}$ is the mutual inductance of the two sets of windings, $i_{\mathrm{b}}, i_{\alpha}$ and $i_{\beta}$ are the currents in b-phase, $\alpha$-phase and $\beta$-phase, respectively. Substituting equation (6) and equation (10) into equation (11), the inductance model of the two sets of windings can be finally written as

$$
\left\{\begin{aligned}
\boldsymbol{L}_{\mathrm{M}} & =L_{2}\left[\begin{array}{cc}
1-\frac{x^{2}}{2 \delta_{0}^{2}} & \frac{-x y}{2 \delta_{0}^{2}} \\
\frac{-x y}{2 \delta_{0}^{2}} & 1-\frac{y^{2}}{2 \delta_{0}^{2}}
\end{array}\right] \\
\boldsymbol{L}_{\mathrm{B}} & {\left[\begin{array}{cc}
L_{4}+L_{0} \cos 4 \gamma_{\mathrm{F}} & M_{4} \sin 4 \gamma_{\mathrm{F}} \\
M_{4} \sin 4 \gamma_{\mathrm{F}} & L_{4}-L_{0} \cos 4 \gamma_{\mathrm{F}}
\end{array}\right] } \\
\boldsymbol{L}_{\mathrm{MB}} & =M_{0}\left[\begin{array}{ll}
A & B \\
C & D
\end{array}\right]+M_{1}\left[\begin{array}{cc}
x & y \\
-y & x
\end{array}\right] \\
& +M_{2}\left[\begin{array}{ll}
x \cos 2 \gamma_{\mathrm{F}} & x \sin 2 \gamma_{\mathrm{F}} \\
y \cos 2 \gamma_{\mathrm{F}} & y \sin 2 \gamma_{\mathrm{F}}
\end{array}\right]
\end{aligned}\right.
$$

where 


$$
\left\{\begin{aligned}
A & =\frac{x}{4} \cos 4 \gamma_{\mathrm{F}}+\frac{y}{2} \sin 4 \gamma_{\mathrm{F}} \\
B & =\frac{x}{4} \sin 4 \gamma_{\mathrm{F}}, C=-\frac{y}{4} \cos 4 \gamma_{\mathrm{F}}+\frac{x}{4} \sin 4 \gamma_{\mathrm{F}} \\
D & =-\frac{x}{4} \cos 4 \gamma_{F}-\frac{y}{4} \sin 4 \gamma_{\mathrm{F}} \\
L_{2} & =\frac{\mu_{0} K^{2} l r w_{2}^{2}}{2 \delta_{0}} \rho, L_{4}=\frac{\mu_{0} K^{2} l r w_{4}^{2}}{2 \delta_{0}} \rho \\
L_{0} & =\frac{\mu_{0} K^{2} l r w_{4}^{2}}{4 \delta_{0}} \sin 4 \rho, M_{4}=\frac{\mu_{0} K^{2} l r w_{4}^{2}}{4 \delta_{0}} \sin 4 \rho \\
M_{0} & =\frac{\mu_{0} K^{2} l r w_{2} w_{4}}{4 \delta_{0}^{2}} \sin 4 \rho, M_{1}=\frac{\mu_{0} K^{2} l r w_{2} w_{4}}{4 \delta_{0}^{2}} \rho \\
M_{2} & =\frac{\mu_{0} K^{2} l r w_{2} w_{4}}{4 \delta_{0}^{2}} \sin 2 \rho
\end{aligned}\right.
$$

\section{B. Inductance model of BPMSM in the 2-phase rotor synchronous coordinate system}

For a simple deduction of radial suspension force model, transforming the above expression of the inductance matrixes into the one in the 2-phase rotor synchronous coordinate system by applying the theory of coordinate transformation. The inductance matrixes in the 2-phase rotor synchronous coordinates can be calculated with

$$
\left\{\begin{array}{l}
L_{\mathrm{Mr}}=C_{2} L_{\mathrm{M}} C_{2}^{\mathrm{T}} \\
L_{\mathrm{Br}}=C_{4} L_{\mathrm{B}} C_{4}^{\mathrm{T}} \\
L_{\mathrm{MBr}}=C_{2} L_{\mathrm{MB}} C_{4}^{\mathrm{T}}
\end{array}\right.
$$

where $\boldsymbol{L}_{\mathrm{Mr}}, \boldsymbol{L}_{\mathrm{Br}}$ and $\boldsymbol{L}_{\mathrm{MBr}}$ are the self-inductances and mutual inductance of the two sets of windings in the 2-phase rotor synchronous coordinate system, respectively.

The transforming matrixes $C_{2}$ and $C_{4}$ can be written as

$$
\left\{\begin{array}{l}
C_{2}=\left[\begin{array}{cc}
\cos \gamma_{\mathrm{F}} & \sin \gamma_{\mathrm{F}} \\
-\sin \gamma_{\mathrm{F}} & \cos \gamma_{\mathrm{F}}
\end{array}\right] \\
C_{4}=\left[\begin{array}{ll}
\cos 2 \gamma_{\mathrm{F}} & \sin 2 \gamma_{\mathrm{F}} \\
-\sin 2 \gamma_{\mathrm{F}} & \cos 2 \gamma_{\mathrm{F}}
\end{array}\right]
\end{array}\right.
$$

According to the parameters of the prototype in TABLE I, the pole arc-width of permanent magnet $2 \rho$ is $\pi$. In this case, substituting equation (12) and equation (15) into equation (14), the inductance model in the 2-phase rotor synchronous coordinate system can be further got as 


$$
\left\{\begin{aligned}
\boldsymbol{L}_{\mathrm{Mr}} & \approx L_{2}\left[\begin{array}{ll}
1 & 0 \\
0 & 1
\end{array}\right] \\
\boldsymbol{L}_{\mathrm{Br}} & =\left[\begin{array}{cc}
L_{4}+\frac{L_{0}+M_{4}}{2} & 0 \\
0 & L_{4}-\frac{L_{0}+M_{4}}{2}
\end{array}\right] \\
\boldsymbol{L}_{\mathrm{MBr}} & =M_{1}\left[\begin{array}{cc}
d & q \\
-q & d
\end{array}\right]
\end{aligned}\right.
$$

where $d$ and $q$ are the eccentric displacement components in the 2-phase rotor synchronous coordinate system. The relationship between $d, q$ and $x, y$ can be written as follows.

$$
\left[\begin{array}{l}
d \\
q
\end{array}\right]=\left[\begin{array}{l}
x \cos \gamma_{\mathrm{F}}+y \sin \gamma_{\mathrm{F}} \\
-x \sin \gamma_{\mathrm{F}}+y \cos \gamma_{\mathrm{F}}
\end{array}\right]
$$

\section{SUSPENSION FORCE MODEL AND CONTROL SYSTEM DESIGN}

The radial suspension forces acting on the rotor in the bearingless motor consist of three parts: 1) the Maxwell forces acting on the rotor in air-gap magnetic field. 2) the reaction forces of the Lorenz forces acting on the currentcarrying torque windings and bearing windings. 3) the radial forces generated by the unbalanced air-gap magnetic field because of rotor eccentricity [10].

According to the principle of virtual displacement, the first and second parts of radial suspension forces can be obtained by the partial derivative of the magnetic field storage on the radial displacements. Therefore, they can be written as [11]

$$
\left[\begin{array}{l}
F_{\text {md }} \\
F_{\text {mq }}
\end{array}\right]=\left[\begin{array}{ll}
\frac{\partial W_{\mathrm{m}}}{\partial d} & \frac{\partial W_{\mathrm{m}}}{\partial q}
\end{array}\right]^{\mathrm{T}}
$$

Since the magnetic energy storage of the motor is reflected as the energy storage of winding inductances excited by the currents, if ignoring the motor magnetic saturation and the magnetomotive force drop in iron core, then the airgap magnetic storage of the BPMSM can be expressed as

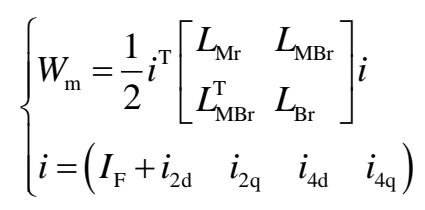

where $I_{\mathrm{F}}$ is the equivalent excitation current of permanent magnet, $i_{2 \mathrm{~d}}, i_{2 \mathrm{q}}$ and $i_{4 \mathrm{~d}}, i_{4 \mathrm{q}}$ are the current components of torque windings and bearing windings in the 2-phase rotor synchronous coordinate system, respectively.

Substituting equation (16) and equation (19) into equation (18), these two parts of radial suspension forces can be got as

$$
\left[\begin{array}{c}
F_{\text {md }} \\
F_{\text {mq }}
\end{array}\right]=M_{1}\left[\begin{array}{cc}
I_{\mathrm{F}}+i_{2 \mathrm{~d}} & i_{2 \mathrm{q}} \\
-i_{2 \mathrm{q}} & I_{\mathrm{F}}+i_{2 \mathrm{~d}}
\end{array}\right]\left[\begin{array}{l}
i_{4 \mathrm{~d}} \\
i_{4 \mathrm{q}}
\end{array}\right]
$$


The third part of radial suspension forces increase with the rotor eccentric displacement and they remain the proportional relationship. As the sinusoidal and symmetry of the air-gap magnetic field, this proportional relationship is equivalent in the d-direction and $\mathrm{q}$-direction $(\mathrm{d}-\mathrm{q}$ coordinate system is 2-phase rotor synchronous coordinate system), therefore, this part of radial suspension forces can be expressed as [12]

$$
\left[\begin{array}{c}
F_{\mathrm{sd}} \\
F_{\mathrm{sq}}
\end{array}\right]=k_{\mathrm{s}}\left[\left(I_{\mathrm{F}}+i_{2 \mathrm{~d}}\right)^{2}+\left(i_{2 \mathrm{q}}\right)^{2}\right]\left[\begin{array}{l}
d \\
q
\end{array}\right]
$$

where $k_{\mathrm{s}}=\frac{9 \mu_{0} l r w_{2}^{2}}{4 \pi \delta_{0}^{2}}$.

According to equation (20) to equation (21), the complete and precise formulation of radial suspension forces can be expressed as

$$
\begin{aligned}
{\left[\begin{array}{c}
F_{\mathrm{d}} \\
F_{\mathrm{q}}
\end{array}\right]=} & {\left[\begin{array}{c}
F_{\mathrm{md}} \\
F_{\mathrm{mq}}
\end{array}\right]+\left[\begin{array}{c}
F_{\mathrm{sd}} \\
F_{\mathrm{sq}}
\end{array}\right] } \\
= & M_{1}\left[\begin{array}{cc}
I_{\mathrm{F}}+i_{2 \mathrm{~d}} & i_{2 \mathrm{q}} \\
-i_{2 \mathrm{q}} & I_{\mathrm{F}}+i_{2 \mathrm{~d}}
\end{array}\right]\left[\begin{array}{l}
i_{4 \mathrm{~d}} \\
i_{4 \mathrm{q}}
\end{array}\right] \\
& +k_{\mathrm{s}}\left[\left(I_{\mathrm{F}}+i_{2 \mathrm{~d}}\right)^{2}+\left(i_{2 \mathrm{q}}\right)^{2}\right]\left[\begin{array}{l}
d \\
q
\end{array}\right]
\end{aligned}
$$

Then in the 2-phase rotor synchronous coordinate system the current commands of bearing windings can be got as

$$
\begin{aligned}
{\left[\begin{array}{c}
i_{4 \mathrm{~d}}^{*} \\
i_{4 \mathrm{q}}^{*}
\end{array}\right]=} & \frac{1}{M_{1}\left[\left(i_{2 \mathrm{~d}}+i_{\mathrm{f}}\right)^{2}+i_{2 \mathrm{q}}^{2}\right]}\left[\begin{array}{cc}
I_{\mathrm{F}}+i_{2 \mathrm{~d}} & -i_{2 \mathrm{q}} \\
i_{2 \mathrm{q}} & I_{\mathrm{F}}+i_{2 \mathrm{~d}}
\end{array}\right]\left[\begin{array}{c}
F_{\mathrm{d}}^{*} \\
F_{\mathrm{q}}^{*}
\end{array}\right] \\
& -\frac{k_{\mathrm{s}}}{M_{1}}\left[\begin{array}{cc}
I_{\mathrm{F}}+i_{2 \mathrm{~d}} & -i_{2 \mathrm{q}} \\
i_{2 \mathrm{q}} & I_{\mathrm{F}}+i_{2 \mathrm{~d}}
\end{array}\right]\left[\begin{array}{l}
d \\
q
\end{array}\right]
\end{aligned}
$$

Based on the above force/current transformation (equation (23)), the control system for the BPMSM can be designed and the corresponding block diagram is shown in Fig. 6. The torque control is realized by the method of rotor field oriented. The displacements $x$ and $y$ in the 2-phase stator coordinate system are detected by eddy-current sensors. Then by use of equation (17), the eccentric displacements $d$ and $q$ in the 2-phase rotor synchronous coordinate system can be obtained. $d$ and $q$ are compared with the given displacements $d^{*}$ and $q^{*}\left(d^{*}=q^{*}=0\right)$, then the differences are regulated by two Proportional-Integral-Derivative (PID) controllers to acquire radial suspension force commands $F_{\mathrm{d}}^{*}$ and $F_{\mathrm{q}}^{*}$ in the 2-phase rotor synchronous coordinate system. On the base of force/current transformation (equation (23)), the current commands of bearing windings $i_{4 \mathrm{~d}}^{*}$ and $i_{4 \mathrm{q}}^{*}$ can be acquired and are further transformed into three phase current commands $i_{4 \mathrm{~A}}^{*}, i_{4 \mathrm{~B}}^{*}$ and $i_{4 \mathrm{C}}^{*}$. Lastly the three phase current commands are modulated by current regulation pulse width modulation (CRPWM) and three practical currents are generated to control the bearing windings. 


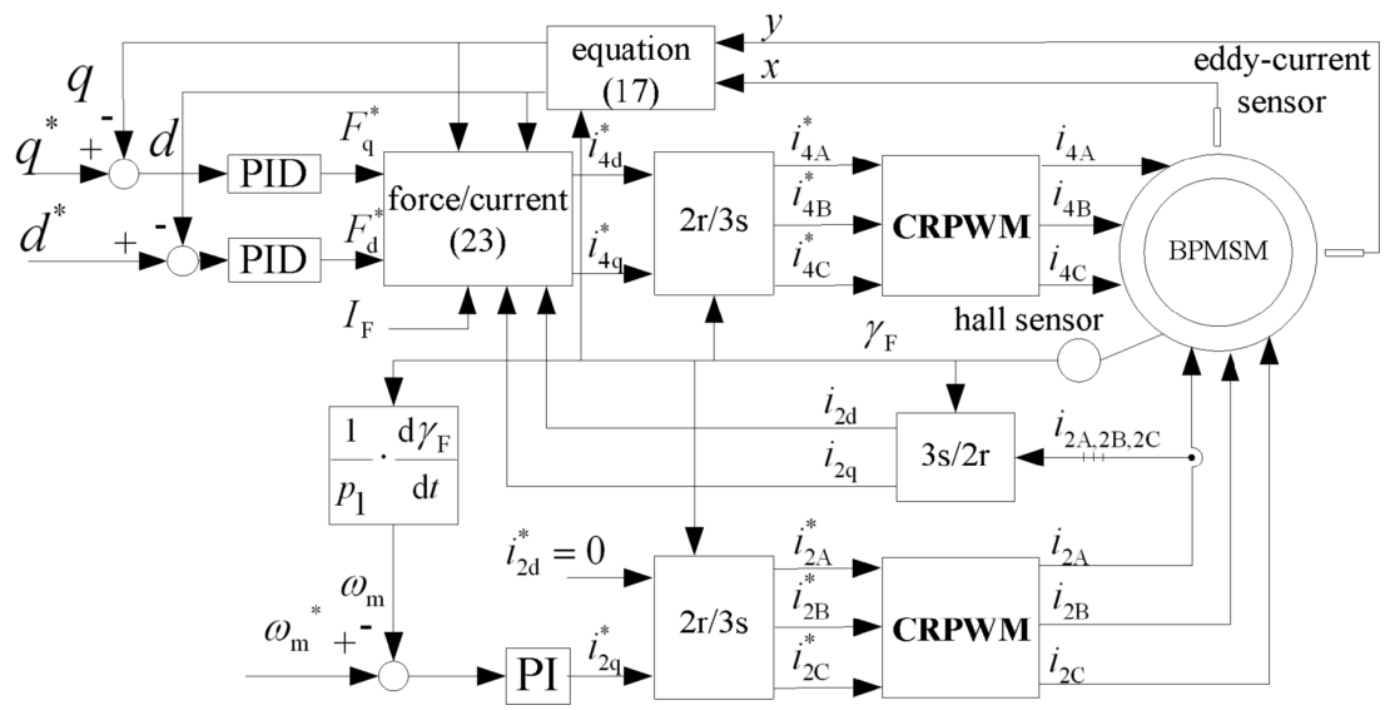

Fig. 6. Control system block diagram

\section{ANALYSIS OF EXPERIMENTAL RESULTS}

An experimental platform is constructed on the basis of the above control system block diagram. TMS320F2812 DSP is used as the digital controller of the experimental platform.

Fig. 7 shows the experiment results. Fig. 7(a) is the waveforms of radial displacements in the $x$ - and y-direction when the motor runs at $1000 \mathrm{r} / \mathrm{min}$. Fig. 7(b) shows the waveform of radial displacement in the $\mathrm{x}$-direction when the rotor speed is changed from $1000 \mathrm{r} / \mathrm{min}$ to $2000 \mathrm{r} / \mathrm{min}$ (the displacement in the y-direction is similar with the one in the x-direction). As can be seen in Fig. 7(b), the vibration amplitude in the x-direction is less than $150 \mu \mathrm{m}$, which is very small compared to the unilateral average air-gap length $(2 \mathrm{~mm})$, this indicates that the slice rotor is still in a stable suspension state. When the speed remains at $1000 \mathrm{r} / \mathrm{min}$, a disturbance force in radial direction is acted on the rotor, Fig. 7(c) shows the waveforms of the displacements in the x-and y-direction. As shown in Fig. 7(c), the slice rotor can be suspended stably again after a short time of unstable suspension. In Fig. 7(d), the accuracy of radial suspension force based on the inductance model is verified by the test values and the finite element analysis (the parameters of the finite element model are based on the BPMSM prototype), and it can be seen that the errors among the three are very small and the control system has high control accuracy of radial suspension force. In the test, the rotor speed can be regulated from $0 \mathrm{r} / \mathrm{min}$ to $2000 \mathrm{r} / \mathrm{min}$ continuously with the steady error less than $2 \mathrm{r} / \mathrm{min}$, the system has good speed regulation performance.

From above analysis, the control system for the BPMSM based on the proposed mathematical model of radial suspension forces has high control accuracy of radial suspension force and strong capability of resisting disturbance, moreover, it has good static and dynamic performance. 


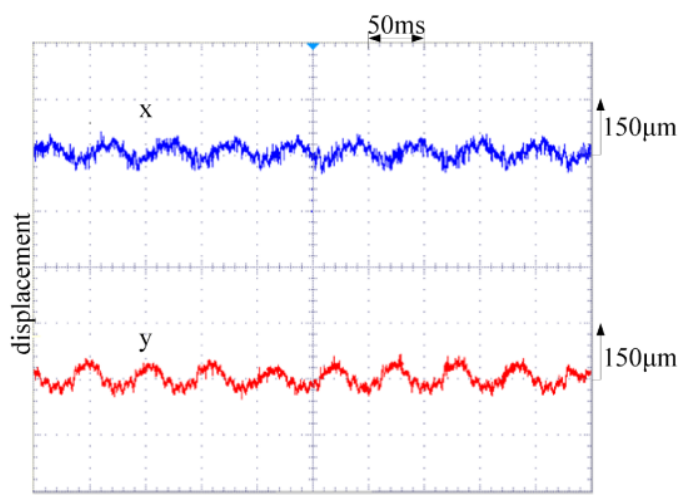

(a) The displacements when the motor runs at $1000 \mathrm{r} / \mathrm{min}$

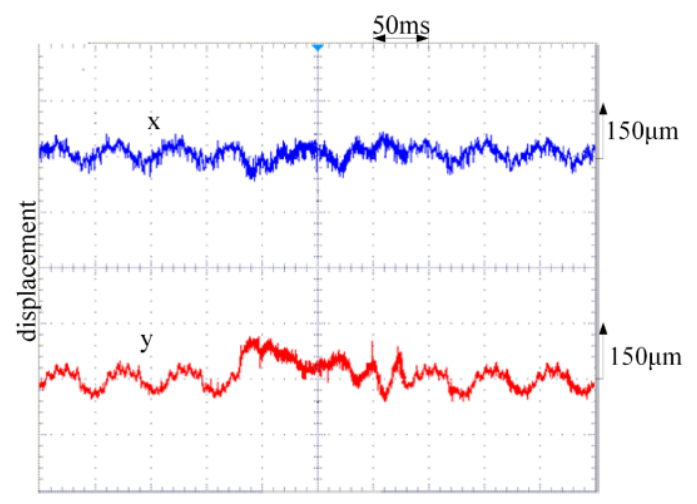

(c) The displacements under a disturbance force

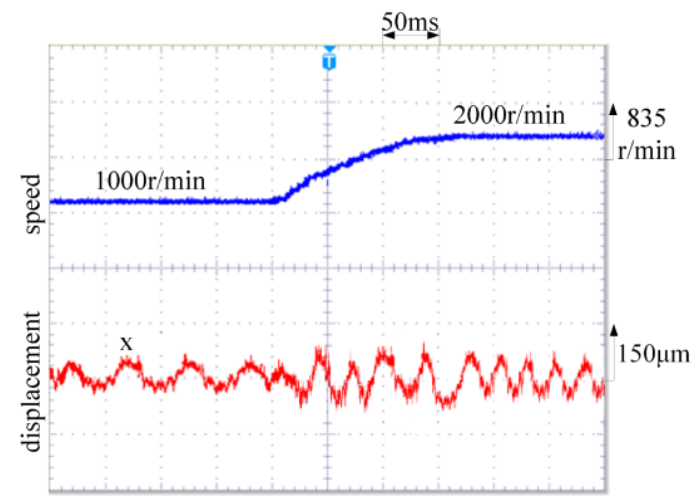

(b) The displacement in the $\alpha$-axis during the speed increase

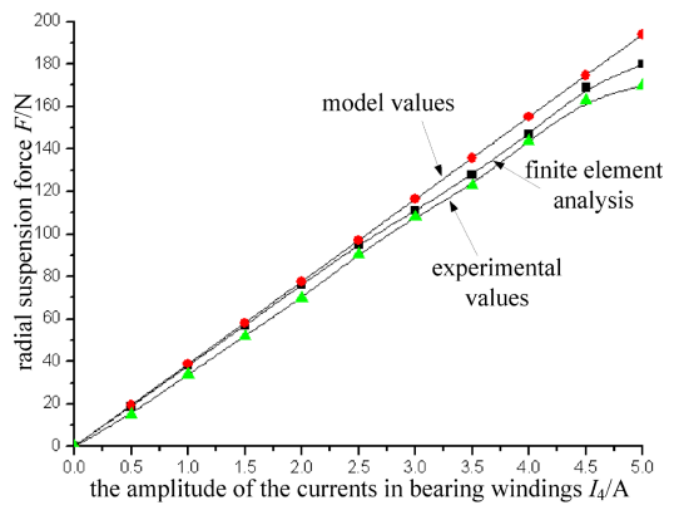

(d) The verification for the control accuracy of radial suspension force

Fig. 7. Experiment results

\section{CONCLUSIONS}

In 2-phase stator coordinate system, the inductance model of the two sets of windings in the BPMSM is relatively complex. Transformed to that in the 2-phase rotor synchronous coordinate system, the model can be simplified greatly, in which the self-inductances of two sets of windings are both consents and the mutual inductance is only related to the displacements in the 2-phase rotor synchronous coordinate system. The control system for the BPMSM based on the proposed mathematical model of radial suspension forces has high control accuracy of radial suspension force, strong capability of resisting disturbance, and good static and dynamic performance.

\section{ACKNOWLEDGMENT}

This work is sponsored by National Natural Science Foundation of China (60974053), Jiangsu Province University Achievements in Scientific Research Industrial Production Advancement Project (JHB2012-39), and the Priority Academic Program Development of Jiangsu Higher Education Institutions ([2011]6).

\section{REFERENCES}

[1] H. Mitterhofer, W. Amrhein, "Design aspects and test results of a high speed bearingless drive," in Int. Conf. Power Electronics and Drive Systems, 2011, pp. 705-710. 
[2] M.T. Bartholet, T. Nussbaumer, S. Silber, J.W. Kolar, "Comparative Evaluation of Polyphase Bearingless Slice Motors for FluidHandling Applications," IEEE Trans. Ind. Appl., vol. 45, no. 5, pp. 1821-1830, Sept./oct. 2009.

[3] X. Sun, L. Chen, and Z. Yang, “Overview of bearingless permanent-magnet synchronous motor,” IEEE Trans. Ind. Electron., vol. 60, no. 12, pp. 5528-5538, Dec. 2013.

[4] Q. Li, P. Boesch, M. Haefliger, J. W. Kolar, et al, "Basic characteristics of a $4 \mathrm{~kW}$ permanent-magnet type bearingless slice motor for centrifugal pump system," in Int.Electrical Machines and Systems, 2008, pp. 3037-3042.

[5] J. Asama, D. Kanehara, T. Oiwa, et al, "Development of a compact centrifugal pump with a two-axis actively positioned consequent-pole bearingless motor," IEEE Trans. Ind. Appl., vol. 50, no. 1, pp. 288-295, Jan/Feb. 2014.

[6] J. Zhu, Z. Deng, X. Wang, "Principle and implementation of the single winding bearingless permanent magnetic slice motor," Proc. CSEE., vol. 28, no. 33, pp. 68-74, Nov. 2008.

[7] Q. Liao, X. Wang, Z. Deng, “Theory and Realization of 3 Pole Pairs Consequent-pole Bearingless Slice Motor,” Proc. CSEE., vol. 28, no. 36, pp. 68-72, Dec. 2008.

[8] X. Sun, L. Chen, and Z. Yang, et al, "Modeling of a bearingless permanent magnet synchronous motor considering rotor eccentricity and coupling relationship of windings," Transactions of China Electrotechnical Society, vol. 28, no. 3, pp. 63-70, Mar 2013,

[9] T. Tera, Y. Yamauchi, A. Chiba, "Performances of bearingless and sensorless induction motor drive based on mutual inductances and rotor displacements estimation," IEEE Trans. Ind. Electron., vol. 53, no. 1, pp. 187-194, Feb. 2006.

[10] M. Ooshima, T. Kurokawa, M. Sakagami, et al, "An identification method of suspension force and magnetic unbalance pull force parameters in buried-type IPM bearingless motors,” IEEE Power Engineering Society General Meeting, 2004, pp. 1276-1279.

[11] Z. Li, Y. Luo, "New method of magnetic force density computation for turbo-generator based on finite element method and virtual work principle,” Proc. CSEE., vol. 29, no. 3, pp. 71-77, Jan. 2009.

[12] W. Zuo, Y. Lv, X. Fu, et al, "Accurate mathematical modeling of radial suspension force on bearingless permanent magnet slice motors," Proc. CSEE, vol. 32, no. 3, pp. 103-110, Jan. 2012.

Huangqiu Zhu received the B. S. degree in Department of Automation from School of Electrical and Information Engineering, Jiangsu University, Zhenjiang, in 1987, received the M. S. degree in Management from Jiangsu University, Zhenjiang, in 1993, and received Ph. D. degree from Nanjing University of Aeronautics and Astronautics, Nanjing, in 2000.

He was a visiting scholar in Swiss Federal Institute of Technology (ETH), Zurich, Switzerland, from November 2002 to November 2003 . He is currently a Professor in the Department of Electrical Engineering, Jiangsu University, Zhenjiang. His research interests include magnetic bearings, magnetic suspension (bearingless) motors, motors and movement control, etc.

Suming Zhu received B.S. degree in Department of Electronic and Information Engineering from School of Electrical and Information Engineering, Jiangsu University, Zhenjiang, in 2012. 
Since 2008, she has been with School of Electrical and Information Engineering, Jiangsu University, Zhenjiang, where he is currently an MD candidate. His research interests include structure parameter design and control technology for bearingless motors. 